\title{
Positive Cumulative Fluids Balance Related to Mortality Events in Sepsis Patients Treated at Intensive Care Unit, Dr. Mohammad Hoesin General Hospital Palembang
}

Zulkifli $^{1}$, Fredi Heru Irwanto ${ }^{1}$, Legiran ${ }^{2}$, Nadia Maharni ${ }^{3 *}$

${ }^{1}$ Department of Anesthesiology and Intensive Therapy, Faculty of Medicine, Universitas Sriwijaya, Palembang, Indonesia

${ }^{2}$ Department of Anatomy, Faculty of Medicine, Universitas Sriwijaya, Palembang, Indonesia

${ }^{3}$ Specialized Residency Training, Department of Anesthesiology and Intensive Therapy, Faculty of Medicine, Universitas Sriwijaya, Palembang, Indonesia

*Corresponding author:

Nadia Maharni

Specialized Residency Training, Department of Anesthesiology and Intensive Therapy, Faculty of Medicine, Universitas Sriwijaya, Palembang, Indonesia

Email:

ndmaharni@yahoo.com

https://doi.org/10.37275/jacr.v2i2.159

\begin{abstract}
Introduction. Sepsis is a syndrome that describes physiological dysfunction, pathological, and biochemistry caused by infection. Fluid balance is an indicator that can monitor input and output. This study was aimed to evaluate the relationship between positive cumulative fluid balance and the mortality rate of sepsis patients treated in the intensive care unit.

Methods: This study design is a retrospective study. The inclusion criteria consist of patients diagnosed with sepsis written in the medical record, 1865 years old, and patients admitted in intensive care unit dr Moh. Hoesin General Hospital. Data were analyzed using SPSS 22.0 with the normality of data distribution, independent sample t-test, Mann-Whitney analysis, chisquare, Fisher's Exact to measure the relationship, and using Medcalc version 14 application to measure cut-off value, ROC curve AUC, crosssectional point, sensitivity, and specificity.
\end{abstract}

Results. The result showed that characteristic between age $(p=0,491)$, gender $(\mathrm{p}=0,703)$ did not differ significantly between survived and nonsurvived patient. Length of stay $(p=0,002)$, balance $(p=0,000)$, and ward unit $(\mathrm{p}=0,014)$ has a significant different between survived and non survived patient. In chi square analysis, $p$ value $=0,000$ with odds ratio 7,083 . Cut-off value of ROC curve is $-97 \mathrm{~mL}$ with AUC 0,844 , sensitivity $76,1 \%$ and specificity $79,3 \%$.

Conclusion. Cumulative positive balance patient in the sepsis patient correlates with increased mortality in a sepsis patient in Dr. Mohammad Hoesin General Hospital Palembang.

Keywords. sequential organ failure assessment (SOFA), intensive care unit, fluid balance, comorbidity, sepsis. 


\section{Journal of Anesthesiology \& \\ Clinical Research}

\section{Introduction}

Sepsis is a physiological, pathological, and biochemical abnormality caused by infection. Sepsis shock is a part of sepsis with circulatory and cellular/metabolic dysfunction associated with a higher risk of death. ${ }^{1}$ Studies in five countries (Argentina, Chile, Colombia, Ecuador, Uruguay) showed 28-day mortality of patients ranging from $34.9 \%$ to $43.4 \% .^{2}$ The previous studies, a study in Egypt in 2019, obtained 28-day mortality of $54.1 \% .^{3}$ For data in Indonesia, based on data from an observational study of patients with sepsis and sepsis shock during 2013 to 2016 found that 8,200 (58.3\%) patients died from 14,076 patients. ${ }^{4}$ Based on patient data of Mohammad Hoesin (RSMH) Palembang in 2017 found that the incidence of sepsis was $30.1 \%$ and 28 -day mortality was $46.8 \% .^{5}$

Sepsis causes profound disturbances at least three determinants of effective artery blood volume (EABV): vascular capacity, cardiac output, and capillary endothelial barrier. Sepsis can be considered a prototype of an acute illness that causes a life-threatening decrease in EABV. An extracellular fluid volume (ECFV) value above the normal range is associated with a favorable outcome in sepsis. The infusion of large volumes of fluids is one of the primary therapeutic modalities in sepsis and sepsis shock. The surviving sepsis campaign (SSC) recommends that, in resuscitation from sepsis-induced hypoperfusion, at least $30 \mathrm{~mL} / \mathrm{kg}$ of IV crystalloid fluid be administered within the first 1 hour. ${ }^{6,7}$ However, from the literature, much evidence shows that the margin of safety for intravenous fluids in sepsis is narrow. ${ }^{8,9}$ The narrow margin of safety means that clinicians must monitor closely because the administration of these fluids can have benefits or disadvantages. The use of fluid balance as an independent predictor in predicting mortality in sepsis patients is cheap and safe to do. This study was aimed to evaluate how the relationship between positive cumulative fluid balance and the mortality rate of sepsis patients treated in the intensive care unit of Dr. Mohammad Hoesin General Hospital Palembang.

\section{Methods}

This study is a retrospective study, the data taken from medical records to determine the relationship between cumulative fluid balance and mortality in sepsis patients. The population and sample in this study were all patients diagnosed with sepsis who were treated in the intensive care room and recorded in the medical records of Dr. Mohammad Hoesin General Hospital Palembang for the period January $1^{\text {st }}-$ December $31^{\text {st }}$, 2020, and has met the inclusion and exclusion criteria. The unpaired analytical minimum sample size formula determined the research sample size. Based on the formula for the number of samples, 


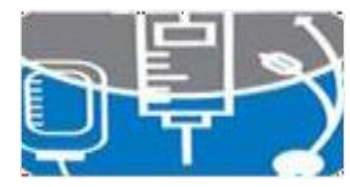

\section{Journal of Anesthesiology \& \\ ClinicalResearch}

the sample size for each group is 77 subjects, so the total sample size is 154 subjects. The inclusion criteria of this study were patients diagnosed with sepsis by a doctor and recorded in the medical record with an age range of 18-65 years and receiving treatment in the intensive care unit of the ICU Dr. Mohammad Hoesin Palembang. The exclusion criteria for this study were patients who did not have complete medical record data, patients with burns, referred or transferred from the intensive care unit of another hospital previously, Patients who were re-admitted to the intensive care unit during the same treatment period. The sampling technique was taken by the consecutive sampling method, using the total sampling technique, where all research samples that met the inclusion and exclusion criteria were taken as research subjects until the number of samples was met. After the data was collected, the data were statistically processed using the SPSS (Statistical Package for Social Science) version 22. A normality test was conducted to determine whether the data were normally distributed or not, and then an independent t-test was performed if the data were normally distributed, and the Mann-test analysis was performed. whitney 7 if the data is not normally distributed. The cumulative fluid balance variable will be searched for the cut-off point using Medcalc version 14 to perform the ROC curve test. Chi-Square and Fisher's Exact tests are used if the data is categorical. Multivariate analysis with regression analysis was also performed to determine the risk factors that most influence sepsis mortality and to obtain an equation model of risk factors for mortality in sepsis patients.

\section{Results}

This study is a retrospective study; the data are secondary data taken from medical records. The population was all patients diagnosed with sepsis who were treated in the intensive care room for January 1-December 31, 2020; the total patient population was 758 patients. Then, subjects as many as 154 subjects match the inclusion criteria. From 154 research subjects, there were 77 subjects with positive cumulative fluid balance and 77 subjects with negative cumulative fluid balance. In positive balance, 61 subjects died, and 16 subjects were alive. Meanwhile, as many as 77 subjects with a negative balance, 26 subjects died, and 51 subjects lived. Characteristics of research subjects can be seen in figure 1 and table 1 . 


\section{Journal of Anesthesiology \& \\ Clinical Research}

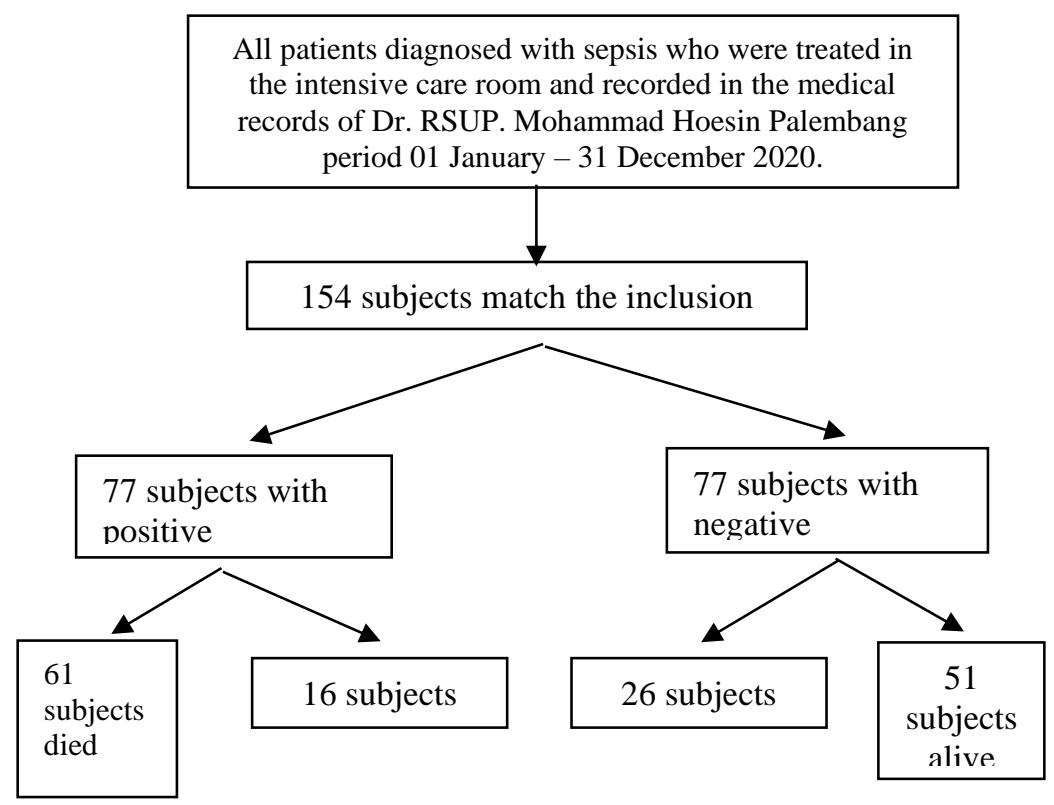

Figure 1. Characteristics of patients.

Table 1. Characteristics of research subjects

\begin{tabular}{|l|c|c|c|}
\hline \multicolumn{1}{|c|}{ Variable } & died & live & $\boldsymbol{p}$ \\
\hline Age, years & $45(20-65)$ & $41(19-65)$ & $0,491^{*}$ \\
\hline $\begin{array}{l}\text { treatment } \\
\text { duration, } \text { days }\end{array}$ & $7(2-20)$ & $6(2-17)$ & $0,002^{*}$ \\
\hline Balance, $m L$ & 1003 & -341 & $0,001^{*}$ \\
\cline { 1 - 3 } & $(-1285-11046)$ & $(-2111-7040)$ & \\
\hline $\begin{array}{l}\text { Lactat level, } \\
\text { mmol }\end{array}$ & $3,2(1,4-5,3)$ & $3,2(1,4-5,3)$ & $0,464^{*}$ \\
\hline $\begin{array}{l}\text { Albumin level, } \\
\text { g/L }\end{array}$ & $3,4(2,5-4,1)$ & $3,2(2,4-4,2)$ & $0,267^{*}$ \\
\hline Gender & $52(59,8 \%)$ & $38(56,7 \%)$ & $0.703^{* *}$ \\
\hline Male & $35(40,2 \%)$ & $29(43,3 \%)$ & \\
\hline Female & $52(59,8 \%)$ & $43(64,2 \%)$ & \\
\hline Hipoalbumin & $35(40,2 \%)$ & $24(35,8 \%)$ & \\
\hline Yes & & & \\
\hline No & & & \\
\hline
\end{tabular}




\section{Journal of Anesthesiology \& \\ Clinical Research}

\begin{tabular}{|c|c|c|c|}
\hline Variable & died & live & $p$ \\
\hline SOFA & & & \multirow[t]{4}{*}{$0,482 * *$} \\
\hline 2-Jan & $2(2,3 \%)$ & $2(3,0 \%)$ & \\
\hline 4-Mar & $15(17,2 \%)$ & $7(10,4 \%)$ & \\
\hline$\geq 5$ & $70(80,5 \%)$ & $58(86,6 \%)$ & \\
\hline \multicolumn{3}{|l|}{ Comorbidity } & \multirow[t]{5}{*}{$0,199 * *$} \\
\hline 0 & $33(37,9 \%)$ & $17(25,4 \%)$ & \\
\hline 1 & $24(27,6 \%)$ & $21(31,3 \%)$ & \\
\hline 2 & $19(21,8 \%)$ & $23(34,3 \%)$ & \\
\hline 3 & $11(12,6 \%)$ & $6(9,0 \%)$ & \\
\hline \multicolumn{3}{|l|}{ Room } & \multirow[t]{4}{*}{$0,014 * *$} \\
\hline GICU & $45(51,7 \%)$ & $44(65,7 \%)$ & \\
\hline ICU ER & $26(29,9 \%)$ & $7(10,4 \%)$ & \\
\hline $\mathrm{P} 1$ & $16(18,4 \%)$ & $16(23,9 \%)$ & \\
\hline \multicolumn{3}{|l|}{$\begin{array}{l}\text { Mechanical } \\
\text { Ventilation }\end{array}$} & \multirow[t]{3}{*}{$\begin{array}{c}0,079 * * \\
*\end{array}$} \\
\hline Yes & $85(97,7 \%)$ & $61(91,0 \%)$ & \\
\hline No & $2(2,3 \%)$ & $6(9,0 \%)$ & \\
\hline \multicolumn{3}{|l|}{ Vasopressor } & \multirow[t]{3}{*}{$0,946 * *$} \\
\hline Yes & $32(36,8 \%)$ & $25(37,3 \%)$ & \\
\hline No & $55(63,2 \%)$ & $42(62,7 \%)$ & \\
\hline \multicolumn{3}{|l|}{ Inotropik } & \multirow[t]{3}{*}{$0,902 * *$} \\
\hline Yes & $32(36,8 \%)$ & $24(35,8 \%)$ & \\
\hline No & $55(63,2 \%)$ & $43(64,2 \%)$ & \\
\hline \multicolumn{3}{|l|}{ Focal Infection } & \multirow[t]{5}{*}{$0,448 * *$} \\
\hline Malignancy & $12(13,8 \%)$ & $15(22,4 \%)$ & \\
\hline Gastrointestinal & $25(28,7 \%)$ & $18(26,9 \%)$ & \\
\hline Urinary Tract & $12(13,8 \%)$ & $11(16,4 \%)$ & \\
\hline Respiratory & $38(43,7 \%)$ & $23(34,3 \%)$ & \\
\hline \multicolumn{2}{|l|}{$\begin{array}{l}\text { operation action } \\
\text { source control }\end{array}$} & & \multirow[t]{3}{*}{$0,423 * *$} \\
\hline Yes & $45(51,7 \%)$ & $39(58,2 \%)$ & \\
\hline No & $42(48,3 \%)$ & $28(41,8 \%)$ & \\
\hline \multicolumn{3}{|c|}{ Note: *: Test using *: Mann-Whitney, } & \\
\hline \multicolumn{4}{|c|}{$* *$ : Chi-Square, $* * *:$ Fisher's Exact $\mathrm{p}<0.05$} \\
\hline significant & & & \\
\hline
\end{tabular}




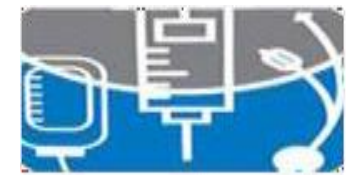

\section{Journal of Anesthesiology \& \\ ClinicalResearch}

Table 1 showed the mean age for patients who died was 45 years and the mean age for patients who lived was 41 years. In the Mann-Whitney analysis test, it was found that there was no difference in the mean age between the groups of patients who died and those who lived with p value $=0.491$. It is also known that the median length of treatment in the group of patients who died was 7 days, while the median value of length of treatment in the group of patients who died was 6 days. In the Mann-Whitney analysis test, there was a significant difference in the average length of treatment in the group of patients who died and the group of patients who lived with $p$ value $=0.002$.

From the data is known that the mean cumulative fluid balance in the dead group is $1003 \mathrm{~mL}$, while in the living group it is $-341 \mathrm{~mL}$. In Mann-Whitney analysis test, there was a significant mean difference between the cumulative fluid balance in the dead group and the living group with $p=0.001$.

In the distribution of lactate levels to mortality, the median value of lactate levels in the dead and living groups is $3.2 \mathrm{mmol}$. In the Mann-Whitney analysis test, there was no difference in the mean lactate levels between the dead and living groups with $\mathrm{p}$ value $=0.464$.

In the distribution of albumin levels on mortality, the mean albumin level in the dead group is 3.4 $\mathrm{g} / \mathrm{L}$, while the median albumin level in the living group is $3.2 \mathrm{~g} / \mathrm{L}$. In the Mann-Whitney analysis test, there was no difference in the mean albumin level between the dead and living groups with $p$ value $=0.267$.

There were $59.8 \%$ male subjects in the group who died and $56.7 \%$ male subjects in the living group. In the chi-square analysis test, the gender did not have a significant relationship with mortality in sepsis patients with $\mathrm{p}$ value $=0.703$.

There were $87.4 \%$ of subjects who did not have a history of kidney failure in the mortality group who died and $88.1 \%$ of subjects who also did not have a history of kidney failure in the living mortality group. In the chi-square analysis test, the history of kidney failure did not have a significant relationship with the mortality of sepsis patients with $\mathrm{p}$ value $=0.895$.

There were $80.5 \%$ no history of heart failure in the mortality group who died, and there were $79.1 \%$ subjects who also did not have a history of heart failure in the living mortality group. From the chi-square analysis test, the history of heart failure did not have a significant relationship with the mortality of sepsis patients with $\mathrm{p}$ value $=0.895$.

There were $59.8 \%$ of subjects with hypoalbumin in the mortality group who died, and there were $64.2 \%$ of subjects with hypoalbumin in the living mortality group. In the chi-square analysis test, hypoalbumin did not have a significant relationship with mortality in sepsis patients with $\mathrm{p}$ value $=0.577$.

There were $80.5 \%$ subjects with SOFA score 5 in the mortality group who died, and there were $86.6 \%$ 


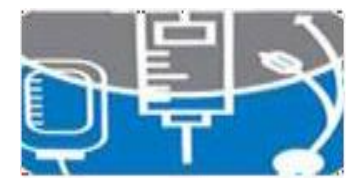

\section{Journal of Anesthesiofogy \& \\ ClinicalResearch}

subjects with SOFA scores 5 in the living mortality group. In the chi-square analysis test, SOFA did not have a significant relationship with mortality in sepsis patients with $\mathrm{p}$ value $=0.482$.

There were $37.9 \%$ subjects with Charlson 0 in the mortality group who died, while there were $34.3 \%$ subjects with Charlson 2 in the living mortality group. In the chi-square analysis test, charlson did not have a significant relationship with the mortality of sepsis patients with $\mathrm{p}$ value $=0.199$.

There were $51.7 \%$ of subjects treated in the GICU room in the mortality group who died, and there were $65.7 \%$ of subjects treated in the GICU room in the living mortality group. In the chi-square analysis test, the origin of the treatment room had a significant relationship with the mortality of sepsis patients with $\mathrm{p}$ value $=0.014$

There were $97.7 \%$ of subjects who used a ventilator in the mortality group who died, and there were as many as $91.0 \%$ of subjects who used a ventilator in the living mortality group. In the fisher's exact test analysis, the use of a ventilator did not have a significant relationship with the mortality of sepsis patients with $\mathrm{p}$ value $=0.079$.

There were $63.2 \%$ of subjects without vasopressor use in the mortality group who died, and there were $62.7 \%$ of subjects without vasopressor use in the living mortality group. In the chi-square analysis test, the use of vasopressors did not have a significant relationship with the mortality of sepsis patients with $\mathrm{p}$ value $=0.946$

There were $63.2 \%$ of subjects without inotropic use in the mortality group who died, and $64.2 \%$ of subjects without inotropic use in the living mortality group. In the chi-square analysis test, the use of inotropes did not have a significant relationship with the mortality of sepsis patients with p value $=0.902$.

There were as many as $43.7 \%$ of subjects with a source of respiratory infection in the mortality group who died, and there were as many as $34.3 \%$ of subjects with a source of infection in the respiratory tract in the living mortality group. In the chi-square analysis test, the source of infection did not have a significant relationship with the mortality of sepsis patients with $\mathrm{p}$ value $=0.448$.

There were $51.7 \%$ of subjects who received source control surgery in the mortality group who died, and there were $58.2 \%$ of subjects who received source control surgery in the living mortality group. In the chi-square analysis test, source control surgery did not have a significant relationship with mortality in sepsis patients with $\mathrm{p}$ value $=0.423$.

The cumulative fluid balance analysis on sepsis mortality can be seen in table 2 . In Table 2 , it was found that as many as $79.2 \%$ of subjects had a positive cumulative fluid balance in the dead group, while there were $66.3 \%$ of subjects with a negative cumulative fluid balance in the living group. In the Chi-Square 


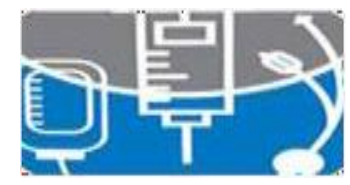

\section{Journal of Anesthesiology \& \\ Clinical Research}

analysis test, the $\mathrm{p}$ value $=0.001$ with an OR of 7.083 which means positive cumulative fluid balance has a 7.083x higher risk for mortality in sepsis patients.

Table 2. Analysis of cumulative fluid balance on sepsis mortality

\begin{tabular}{|c|c|c|c|c|c|}
\hline \multirow{2}{*}{$\begin{array}{l}\text { Cumulative } \\
\text { fluid balance }\end{array}$} & \multicolumn{2}{|c|}{ Mortality } & \multirow[b]{2}{*}{$\mathbf{p}$} & \multirow[b]{2}{*}{ OR } & \multirow{2}{*}{$\begin{array}{c}\text { CI } \\
95 \%\end{array}$} \\
\hline & Died & Alive & & & \\
\hline $\begin{array}{c}\text { Positive } \\
\text { cumulative } \\
\text { balance }\end{array}$ & $61(79,2 \%)$ & $16(20,8 \%)$ & \multirow{2}{*}{0,001} & \multirow{2}{*}{7,083} & \multirow{2}{*}{$\begin{array}{r}3,440- \\
14,586\end{array}$} \\
\hline $\begin{array}{c}\text { Negatif } \\
\text { cumulative } \\
\text { balance }\end{array}$ & $26(33,7 \%)$ & $51(66,3 \%)$ & & & \\
\hline \multicolumn{4}{|c|}{ Note: Test using Chi-Square, $\mathrm{p}<0.05$} & & \\
\hline significant & & & & & \\
\hline
\end{tabular}

A sensitivity and specificity analysis test was conducted to determine the cut-off of fluid balance that affects mortality in sepsis patients using the ROC Curve. In the ROC analysis test, the fluid balance had a cut-off of $-97 \mathrm{~mL}$ with a sensitivity of $76.1 \%$ and a specificity of $79.3 \%$. It is also known that the AUC value in this study was 0.844 with a $\mathrm{p}$ value of $<0.0001(95 \%$ CI $0.777-0.898)$. Youden Index in this study is 0.554 .

Table 3. ROC Curve analysis on fluid balance to predict sepsis mortality

\begin{tabular}{c|c|c|c|c|c}
\hline $\begin{array}{c}\text { intersec } \\
\text { tion } \\
\text { point }\end{array}$ & AUC & Sensitivity & Specificity & LR + & LR - \\
\hline$-97 \mathrm{~mL}$ & 0,844 & $76,1 \%$ & $79,3 \%$ & 3,68 & 0,30 \\
\hline
\end{tabular}



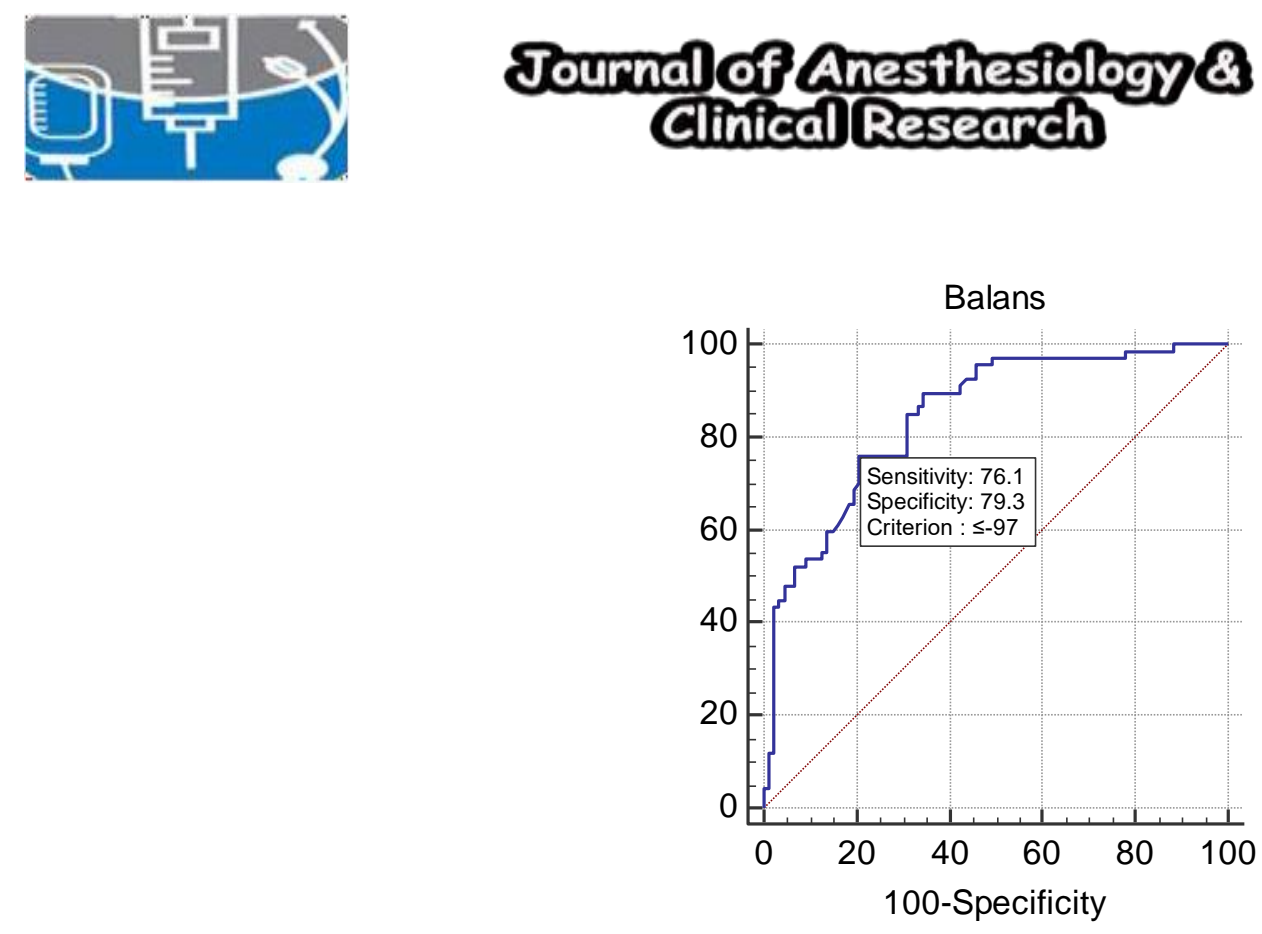

Figure 2. ROC Curve analysis on fluid balance to predict sepsis mortality

Table 4. Total fluid balance against mortality per categorical

\begin{tabular}{|c|c|c|}
\hline Fluid Balance & Died & Alive \\
\hline $\mathbf{- 5 0 0 0}$ SD $\mathbf{- 1 0 0 1}$ & $2(16,7 \%)$ & $10(83,3 \%)$ \\
$\mathbf{- 1 0 0 0}$ sd $\mathbf{- 1 0 1}$ & $16(30,2 \%)$ & $37(69,8 \%)$ \\
$\mathbf{- 1 0 0}$ sd 0 & $9(69,2 \%)$ & $4(30,8 \%)$ \\
$\mathbf{+ 1 0 1}$ sd +999 & $16(55,2 \%)$ & $13(44,8 \%)$ \\
$\mathbf{+ 1 0 0 0}$ sd +4999 & $26(92,9 \%)$ & $2(7,1 \%)$ \\
$\mathbf{+ 5 0 0 0}$ sd +9999 & $15(93,8 \%)$ & $1(6,3 \%)$ \\
\hline$>+10000$ & $3(100 \%)$ & $0(0 \%)$ \\
\hline
\end{tabular}

Table 4 showed the highest number of mortality was found in fluid balance +1000 to +4999 with a total mortality of 26 (92.9\%). Meanwhile, the lowest number of mortality was found in the group with a balance of -5000 to -1001 as many as $2(16.7 \%)$. All research subjects with balance $>+10000$ as many as 3 subjects died, and none were alive.

\section{Discussion}

\section{Subject characteristics}

In this study, there were 154 research subjects who met the inclusion and exclusion criteria. A total of 77 study subjects had a positive cumulative fluid balance and 77 study subjects had a negative cumulative 


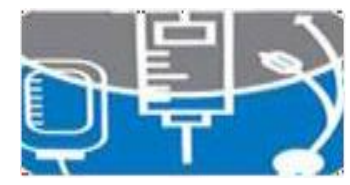

\section{Journal of Anesthesiology \& \\ Clinical Research}

fluid balance. Based on Table 1, it is known that the length of stay, cumulative fluid balance, and origin of hospitalization had significant differences between the living and dead groups with p-values of 0.002 , 0.001, and 0.014, respectively, while there was no difference in the mean between the groups of patients who died and the group who live for variables for age, lactate levels and albumin levels in this study.

Jones et al stated that normal physiological changes during aging increase with electrolyte disturbances in elderly patients undergoing surgery. The most important changes are a decrease in the glomerular filtration rate, a decrease in the ability to concentrate urine, and a narrowing of the ability to excrete water, sodium, potassium, and acids. This normal variation can be controlled by the homeostatic state of fluid and electrolyte balance in elderly patients with normal variations in intake and output. It is suitable as the research that has been done, from the data on the characteristics of the subject, there was no significant relationship between patients who died and those who lived with $\mathrm{p}$ value $=0.491 .^{10}$

In this study, there was no significant relationship between the renal failure variables. Based on Acheampong's study in 2015 found that every $1 \mathrm{~L}$ increase in cumulative fluid balance at 72 hours of ICU admission was independently associated with hospital mortality in all patients, adjusted odds ratio (aOR) 1.06, 95\% CI (1.04 -1.08), $\mathrm{p}<0.001$, and in each AKI/CKD subgroup: aOR 1.06 (1.03-1.09) in patients with AKI/CKD; 1.09 (1.05-1.13) in patients with CKD; 1.05 (1.03 to 1.08) in patients with AKI; and 1.07 (1.02-1.11) in patients without AKI/CKD. There was a significant interaction between AKI and CKD on cumulative fluid balance with $\mathrm{p}$ value $=0.005$. In Neyra's study, the different cumulative fluid cutoffbalances were also found so that the prognostic accuracy for sepsis mortality in hospitals could be better. 5.9 L in patients with $\mathrm{AKI} / \mathrm{CKD} ; 3.8 \mathrm{~L}$ in patients with $\mathrm{CKD}$; $4.3 \mathrm{~L}$ in patients with $\mathrm{AKI}$; and $1.5 \mathrm{~L}$ in patients without $\mathrm{AKI} / \mathrm{CKD}$, but no similar study was found for heart failure. ${ }^{11}$

In the SOFA score variable in this study, the SOFA score did not have a significant relationship to sepsis mortality, but based on Liu's research in 2019, it was found that the SOFA score had an AUC value of $0.686(0.661-0.710)$ with a sensitivity value of $54.5 \%$ and a specificity of $72 ., 5 \% .{ }^{12}$ These different results were obtained due to the difference in the amount of data between the two studies. In the Charlson score variable, the use of support, both ventilator and vasopressor or inotropic, as well as the source of infection or source control surgery in this study did not have a significant relationship to sepsis mortality. It is because the data in this study have the same percentage between the dead and alive groups, so this may be different from other studies. 


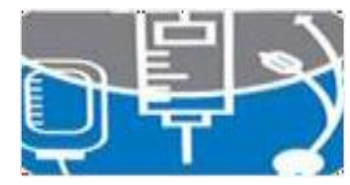

\section{Journal of Anesthesiology \& \\ Clinical Research}

\section{Analysis of the relationship between cumulative fluid balance and sepsis mortality.}

Table 2 showed that as many as $79.2 \%$ of subjects had positive cumulative fluid balance in the dead group, while $66.3 \%$ of subjects with negative cumulative fluid balance in the living group. From Chi-Square analysis test, the $\mathrm{p}$ value $=0.000$ with an $\mathrm{OR}$ of 7.083 , which means positive cumulative fluid balance has a 7.083x higher risk for mortality in sepsis patients.

Mortality in sepsis that can cause multiple organ dysfunction, one of them was respiratory failure which usually caused by uncontrolled interactions and complex interactions between inflammatory cytokines and cellular mediators that damage the alveocapillary unit and divided into several phases, one of them was the exudative phase, which characterized by the presence of edema and alveolar hemorrhage in the first days, a proliferative phase, characterized by organization and repair, and a fibrotic phase, usually occurring 3-4 weeks after the onset of respiratory failure and characterized by collagen fibrosis. ${ }^{13}$

Generalized endothelial activation increases the expression of a number of leukocyte adhesins, with increased leukocyte transmigration into tissues. Endothelial permeability is also increased, in the lung causing interstitial pulmonary edema and in the intestine increasing bacterial translocation, potentially exacerbating the inflammatory cascade initiated by microbial products. ${ }^{14}$

Altered coagulation is very common in sepsis. Endothelial damage leads to loss of the protective function of the natural anticoagulation protein $\mathrm{C}$ pathway and converts the endothelium to a prothrombotic surface. In addition, bacterial products and inflammatory cytokines activate tissue factor, which promotes blood clotting from the extrinsic pathway. This prothrombotic state can cause microvascular blockage and cause coagulopathy in the form of disseminated intravascular coagulation. Gram-positive products can also directly activate the blood clotting system.

In the most severe cases of lethal sepsis, autopsy studies show little evidence of cell death, despite widespread organ dysfunction. The molecular basis is still unclear, although a general reduction in energy expenditure by cells suggests some sort of hibernation process. Along with these changes in cellular function, many metabolic changes, especially increased insulin resistance catabolism and hyperglycemia.

Endothelial boundaries have fenestrations, which vary between organs and in some vascular variations. The integrity of endothelial cells as a barrier and fluid transporter is determined mainly by the endothelial cytoskeleton and the glycocalyx. The glycocalyx is a gel-like layer with a thickness of 0.2-0.5 $\mathrm{m}$ on the luminal membrane of the endothelial boundary, which can reduce $20 \%$ of the intravascular volume. The glycocalyx is a multicomponent layer containing protegolicans (of which 50\%-90\% is heparin) and glycoproteins, bound to endothelial cells by glycosaminoglycans. The presence of oxygen, 


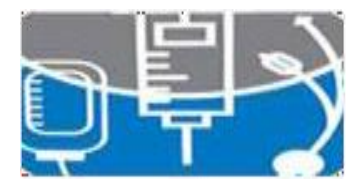

\section{Journal of Anesthestology \& \\ ClinicalResearch}

hyperglycemic conditions, cytokines, and bacterial endotoxins can damage the glycocalyx structure, and associated with several disease conditions including sepsis. The glycocalyx is mediated by several physiological processes such as vascular barrier function, hemostasis, leukocytes, platelet adhesion, transmission of endothelial tears, and anti-inflammatory and antioxidant defenses. Reactive oxygen species (ROS) such as hydrogen peroxide, hydroxyl anions, and superoxide, including tumor necrosis factor (TNFa) and heparinase are mediators that can damage the glycocalyx. These mediators can damage the endothelium and impair barrier function. Loss of barrier function due to mediators that can damage the glycocalyx can be closely associated with the occurrence of edema and a pathogenesis of sepsis induced by organ failure. These things can lead to excess fluid accumulation that leads to multiple organ dysfunction and an increased risk of death. ${ }^{15}$

In general, the occurrence of sepsis can cause endothelial dysfunction that leads to capillary leakage, excessive fluid accumulation in the interstitial space which is also characterized by the presence of a damaged glycocalyx. This gel-like breakdown of glycocalyx causes an increase in capillary permeability, which can lead to multiple organ dysfunction and an increased risk of death.

In sepsis patients who had received fluid resuscitation with the inclusion criteria for the diagnosis of sepsis, aged 18-65 years, were admitted to the ICU. Patients who do not have complete medical record data, patients who are referred or transferred from the intensive care unit of the previous hospital, patients who are treated in the intensive care unit of Dr. Mohammad Hoesin Palembang <24 hours, the patient was readmitted to the intensive care unit in the same treatment period. The confounding variables in this study were age, gender, hypoalbumin, SOFA score, comorbidities, patient care room origin, lactate pepper, albumin level, mechanical ventilation, vasopressor, inotropic, source of infection, and source control surgery. This fluid resuscitation study assessed the patient's positive cumulative fluid balance measured from the first day of hospitalization until the patient died/was discharged from the intensive care unit, as well as assessed the negative cumulative fluid balance of the patient measured from the first day of hospitalization until the patient died/was discharged from the intensive care unit.

\section{ROC Curve analysis on fluid balance to predict sepsis mortality.}

Based on the results of the ROC curve analysis, the fluid balance had a cut-off of $-97 \mathrm{~mL}$ with a sensitivity of $76.1 \%$ and a specificity of $79.3 \%$. It is also known that the AUC value in this study was 0.844 with a $\mathrm{p}$ value of $<0.0001$ (CI95\% $0.777-0.898$ ). Youden Index in this study is 0.554 . The likelihood ratio value is also +3.68 , while the likelihood ratio - is 0.30 . 


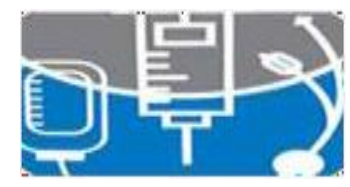

\section{Journal of Anesthestology \& \\ ClinicalResearch}

Chao in 2015 found that in the dead group, the accumulation of positive fluid balance was higher at 48,72 , and 96 hours with statistically significant differences compared to the living group. In addition, Sirvent also found a significant difference $(P=0.02)$ in the survival curve with the risk of death with 72 hours fluid balance $>2.5 \mathrm{~L}$ versus $<2.5 \mathrm{~L}$ from accumulated fluid balance. ${ }^{12}$

Evans in 2016 found that the cumulative fluid balance increased from 1,217mL ( -90 to 2,783mL) in the first 24 hours after admission to the ICU to $1,794 \mathrm{~mL}$ ( -951 to $5,108 \mathrm{~mL}$ ) on day 3 and decreased thereafter. Fluid balance appears to be more likely to be negative in living patients because of the higher fluid output in these patients. Fluid balance became negative after the third ICU day in the living patient but remained positive in the deceased patient. ${ }^{26}$

The endothelial glycocalyx can hydrostatically retain plasma proteins that forced out of the vascular wall. In experimental studies, ischemia/reperfusion, tumor necrosis factor- $\alpha$, and atrial natriuretic peptide (ANP) can cause destruction of these structures. Hypervolemia triggers the release of atrial nariuretic peptide, preventing the occurrence of intravascular hypervolemia, preserving the endothelial glycocalyx and preventing the transfer of protein-rich plasma and interstitial edema. The state of hypervolemia has been shown to worsen the patient's outcome. ${ }^{13}$

Kaukonen in 2016 stated that achieving volume status management requires strong pathophysiological knowledge, evaluation of volume status, appropriate fluid selection, and maintenance and modulation of tissue perfusion. Crystalloid fluid administration is recommended in the initial management of patients at risk for acute heart failure, as well as in patients with sepsis, which expands the extracellular compartment, but in critically ill patients who have increased intravenous capillary leakage, fluid will leak out of the circulation and be distributed in the extracellular volume leading to edema. and excess fluid. This results in impaired diffusion of oxygen and metabolism, disruption of tissue architecture, obstruction of capillary blood flow and lymphatic drainage, and impaired interactions between cells that can lead to organ dysfunction. It is more prominent in organs such as the liver and kidneys. Fluid overload is not only caused by excessive fluid therapy, but also occurs during severe sepsis due to the release of complement factors, cytokines and prostaglandin products and disruption of organ microcirculation. ${ }^{14}$

Mortality in sepsis that can cause multiple organ dysfunction was respiratory failure, usually caused by uncontrolled and complex interactions between inflammatory cytokines and cellular mediators that damage the alveocapillary unit and divided into several phases, one of them is the exudative phase, which characterized by the presence of edema and alveolar hemorrhage in the first days, a proliferative phase, characterized by organization and repair, and a fibrotic phase, usually occurring 3-4 weeks after the onset 


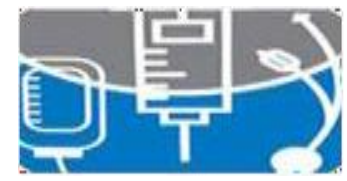

\section{Journal of Anesthestology \& \\ ClinicalResearch}

of respiratory failure and characterized by collagen fibrosis. ${ }^{15}$

\section{Comparison of fluid balance to total mortality}

Table 4 shows that the percentage of study subjects who died was more in patients with positive fluid balance, where all study subjects with fluid balance $>+10000$ died as much as $100 \%$. This is same with research conducted by Angela in 2015, she found that out of 173 patients, 59 died (34\%). The mean daily fluid intake was higher in the dead group than in the living group $(59 \pm 24 \mathrm{ml} / \mathrm{kg} \mathrm{vs} .48 \pm 23 \mathrm{ml} / \mathrm{kg}, \mathrm{p}=$ 0.03), but both groups had similar volumes of output. Persistent positive fluid balance over time is associated with increased mortality. In a time-dependent Cox multivariable model analysis, positive fluid balance was independently associated with higher mortality (adjusted hazard ratio 1.014 [1.007-1.022] per $\mathrm{ml} / \mathrm{kg}$ increase, $\mathrm{p}<0.001 .^{11}$

\section{Conclusion}

The cumulative fluid balance of positive sepsis patients has a significant relationship to the increased mortality of sepsis patients treated in the intensive care unit of Dr. Mohammad Hoesin Palembang with $p$ value $=0.001$.

\section{References}

1. Singer M, Deutschman CS, Seymour CW, Shankar-Hari M, Annane D, Bauer M, et al. The third international consensus definitions for sepsis and sepsis shock (sepsis-3). JAMA. 2016.

2. Liu V, Escobar GJ, Greene JD, Soule J, Whippy A, Angus DC, et al. Hospital deaths in patients with sepsis from 2 independent cohorts. JAMA. 2014.

3. Rudd KE, Johnson SC, Agesa KM, Shackelford KA, Tsoi D, Kievlan DR, et al. Global, regional, and national sepsis incidence and mortality, 1990-2017: analysis for the global burden of disease study. The Lancet. 2020.

4. Purba A, Mariana N, Aliska G, Wijaya S. The burden and costs of sepsis and reimbursement of its treatment in a developing country: an observational study on focal infections in Indonesia. IJID. 2020.

5. Lestari MI, Sedono R, Zulkifli dan Maritska Z. How closely is protein carbonyl (PCO) level correlated with sepsis-related organ function assessment (SOFA) score?. Int J App Pharm. 2020.

6. Roumelioti M-E, Glew RH, Khitan ZJ, Rondon-Berrios H, Argyropoulos CP, Malhotra D, et al. Fluid balance concepts in medicine: principles and practice. World J Nephrol. 2018. 


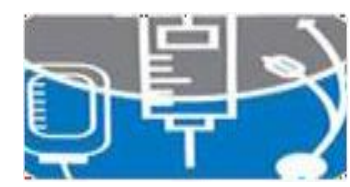

\section{Journal of Anesthesiology \& \\ Clinical Research}

7. Malbrain MLNG, Marik PE, Witters I, Cordemans C, Kirkpatrick AW, Roberts DJ, et al. Fluid overload, de-resuscitation, and outcomes in critically ill or injured patients: a systematic review with suggestions for clinical practice. Anestezjol. Intens. Ter. 2014.

8. Rhodes A, Evans LE, Alhazzani W, Levy MM, Antonelli M, Ferrer R, et al. Surviving sepsis campaign: international guidelines for management of sepsis and sepsis shock: 2016. Intensive Care Med. 2017

9. Rivers E, Nguyen B, Havstad S, Ressler J, Muzzin A, Knoblich B, et al. Early goal-directed therapy in the treatment of severe sepsis and sepsis shock. NEJM. 2001.

10. Jones CH, Akbani H, Croft D. C., Worth D. P. The Relationship Between Serum Albumin and Hydration Status in Hemodiaysis Patients. J. Ren. Nutr. 2002; 12(4): 209-212.

11. Acheampong A, Vincent J-L. A positive fluid balance is an independent prognostic factor in patients with sepsis. Crit. Care. 2015.

12. Chao W-C, Tseng C-H, Chien Y-C, Sheu C-C, Tsai M-J, Fang W-F, et al. Association of day 4 cumulative fluid balance with mortality in critically ill patients with influenza: a multicenter retrospective cohort study in Taiwan.PLOS ONE. 2018.

13. Evans T. Diagnosis and management of sepsis. J. Clin. Med. 2018; 146-9.

14. Kaukonen K-M, Bailey M, Pilcher D, Cooper DJ, Bellomo R. Systemic inflammatory response syndrome criteria in defining severe sepsis. NEJM. 2015; 1629-38.

15. Shankar-Hari M, Phillips GS, Levy ML, Seymour CW, Liu VX, Deutschman CS, et al. Developing a new definition and assessing new clinical criteria for sepsis shock. JAMA. 2016; 23; 315(8): 775. 